\title{
Pulmonary Arterial Hypertension as a Fatal Complication of Neurofibromatosis Type 1 in a Neonate: A Diagnostic Dilemma
}

\author{
Sinan Yavuz ${ }^{1}$, Mona K. Abdullah ${ }^{2}$, Nader Francis ${ }^{3}$ \\ 1. Department of Pediatrics/ Specialist Pediatric, Al Qassimi Women and Children Hospital, Sharjah, ARE 2. \\ Department of Pediatrics /Consultant Pediatrics and Neonatology, Al Qassimi Women and Children Hospital, Sharjah, \\ ARE 3. Department of Pediatrics/ Consultant Pediatric Pulmonology, Al Qassimi Women and Children Hospital, \\ Sharjah, ARE
}

Corresponding author: Sinan Yavuz, syavuz31@hotmail.com

\begin{abstract}
Neurofibromatosis type 1 (NF1), or von Recklinghausen disease, is a genetically transmitted autosomal dominant disease, with a prevalence of one per 4000 live births. Pulmonary arterial hypertension (PAH) is a rare but potentially life-threatening complication of NF1. There are no confirmatory data about the congenital association between PAH and NF1. However, in most cases, PAH is observed in late childhood or adulthood. Herein, we present a preterm baby with genetically confirmed NF1 who presented with PAH.
\end{abstract}

Categories: Genetics, Pediatrics, Pulmonology

Keywords: neurofibromatosis type 1 (nf-1), idiopathic pulmonary arterial hypertension, genetic syndromes, congenital disease, preterm neonate

\section{Introduction}

Neurofibromatosis type 1 (NF1), or von Recklinghausen disease, is an autosomal dominant multisystem disease, with a prevalence of approximately one per 4000 live births. It is characterized by café au lait macules, axillary and inguinal freckling, and benign neurofibromas with Lisch nodules. Further, the other manifestations are cardiovascular, gastrointestinal, renal, and endocrine system abnormalities and peripheral and central nervous system malignancies [1].

Review began $07 / 28 / 2021$ Review ended 08/04/2021 Published 08/12/2021

\section{(c) Copyright 2021}

Yavuz et al. This is an open access article distributed under the terms of the Creative Commons Attribution License CC-BY 4.0., which permits unrestricted use, distribution, and reproduction in any medium, provided the original author and source are credited.
Due to defects in circulatory system adaptation at birth, resulting in persistently high pulmonary vascular resistance, pulmonary arterial hypertension $(\mathrm{PAH})$ is considered a life-threatening disease among newborns [2]. The essential treatment is inhaled nitric oxide, which improves oxygenation without causing systemic hypotension, with an incidence of only two per 1000 live births [3].

Diffuse lung involvement can be observed in NF1 [4,5]. Based on the recently updated classification, PAH associated with neurofibromatosis with unclear and/or multifactorial mechanisms is classified under group 5 [6]. However, there are no clear data about the association between PAH and neurofibromatosis in the neonatal age group.

Herein, we report a preterm baby who was born at 27 weeks, four days gestational age. He was admitted to the neonatal intensive care unit after delivery because of respiratory distress. With consideration of clinical, radiological, and echocardiography findings, treatment failure, and a previous history of three abortions of unknown causes, the baby was suspected of congenital lung developmental disorders. Therefore, we decided to send whole-exome sequencing (WES), which showed the homozygous NF1 (NM_000267.3) variant (c.7127$1=/ \mathrm{G}>\mathrm{T} \mathrm{P})$.

\section{Case Presentation}

The preterm male baby was delivered at 27 weeks and four days of gestational age, and he weighed $1180 \mathrm{~g}$. He was born to a 32-year-old gravida 7, para 3, abortion 3, a known case of dextrocardia, via emergency cesarean section due to preterm premature rupture of the membranes (PPROM) for $33 \mathrm{~h}$. The antenatal follow-up results were unremarkable. The Apgar scores were 6 at $1 \mathrm{~min}, 8$ at $5 \mathrm{~min}$, and 9 at $10 \mathrm{~min}$.

The golden hour measures were applied, and treatment with continuous positive airway pressure (CPAP) was started. Then, the baby was transferred to the neonatal intensive care unit due to respiratory distress. Chest radiography revealed bilateral diffused granular infiltration (Figure 1). 


\section{Cureus}

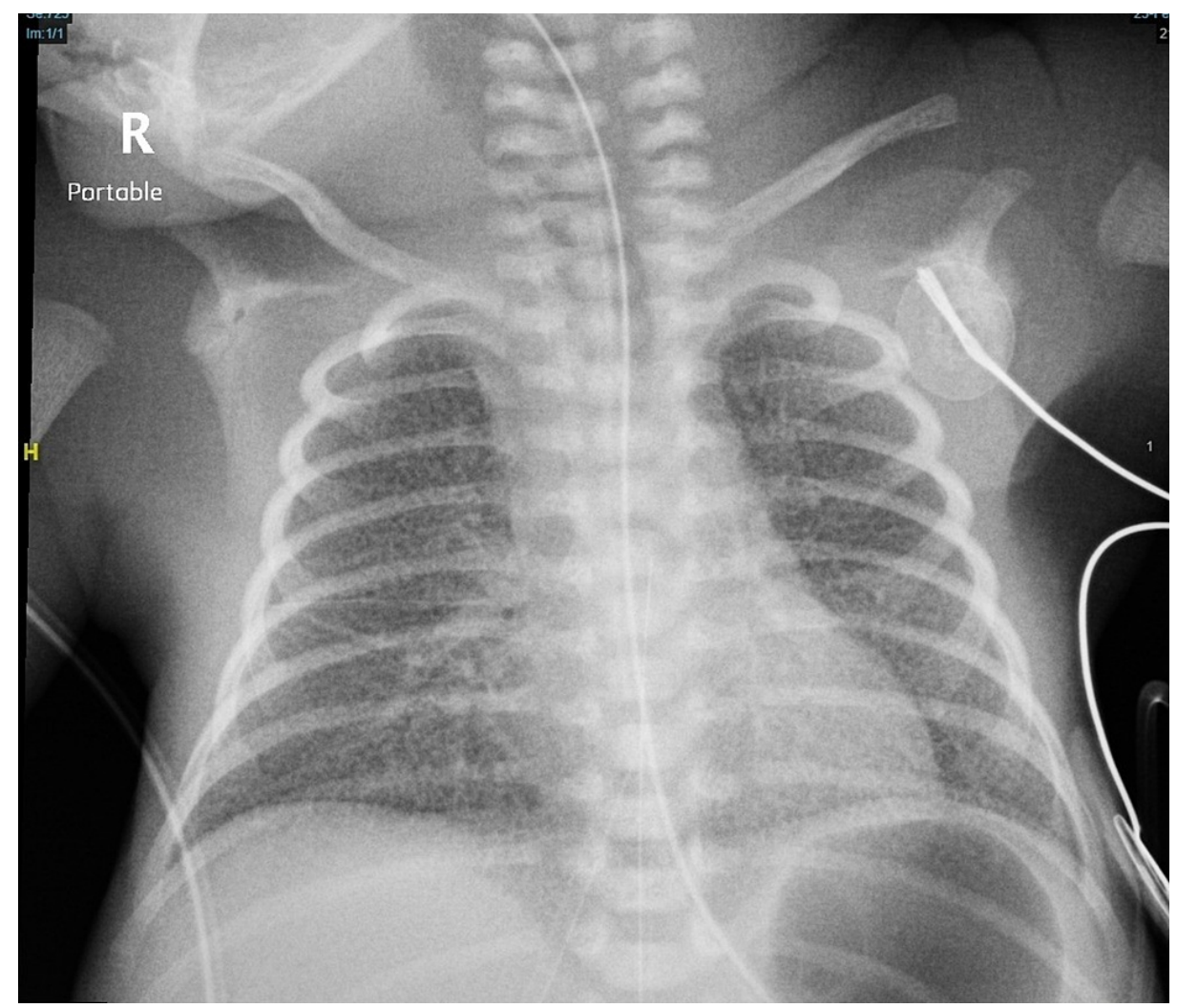

FIGURE 1: Chest radiography revealed bilateral diffused granular infiltration.

The initial complete blood count, C-reactive protein, and electrolyte levels were normal. Moreover, blood culture was performed, and antibiotic therapy was then started. The baby had a stable respiratory status with acceptable oxygen saturation (SpO2) and other blood gas parameter levels for his gestational and postnatal ages. Therefore, CPAP was reduced gradually.

At 13 hours of age, the baby started to desaturate, which required a higher level of nasal continuous positive airway pressure (NCPAP) support. Then, the patient developed apnea. Hence, he needed intubation, and the first dose of surfactant was administered. However, the baby's SpO2 level was not maintained while on maximum conventional ventilation support. Therefore, the respiratory support was switched to highfrequency oscillatory ventilation. Despite the latter treatment, the baby continued to desaturate. Repeat chest radiography showed worsening respiratory distress syndrome but no pneumothorax (Figure 2). 


\section{Cureus}

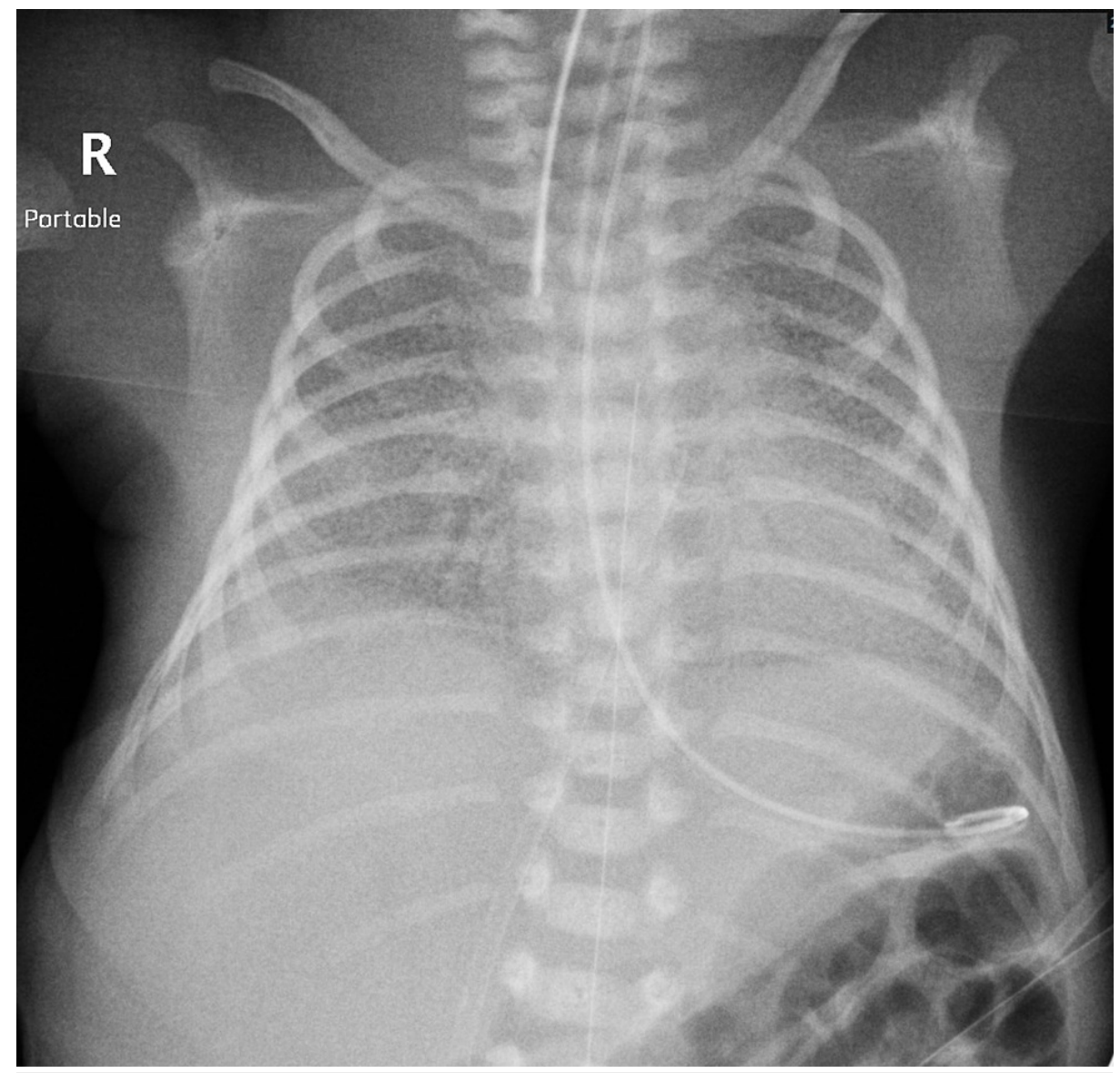

FIGURE 2: Chest radiography showed worsening respiratory distress syndrome but no pneumothorax.

Then, the baby received two extra doses of surfactant. Based on the presence of hypoxic respiratory failure, PAH was suspected clinically, and inotropic support was started.

The echocardiographic assessment showed a large patent ductus arteriosus with severe PAH and mild dilation of the right ventricle in addition to mild globally impaired ventricular functions. Therefore, the baby was treated with inhaled nitric oxide.

His condition continued to deteriorate with a better expansion of both lung fields (Figure 3). 


\section{Cureus}

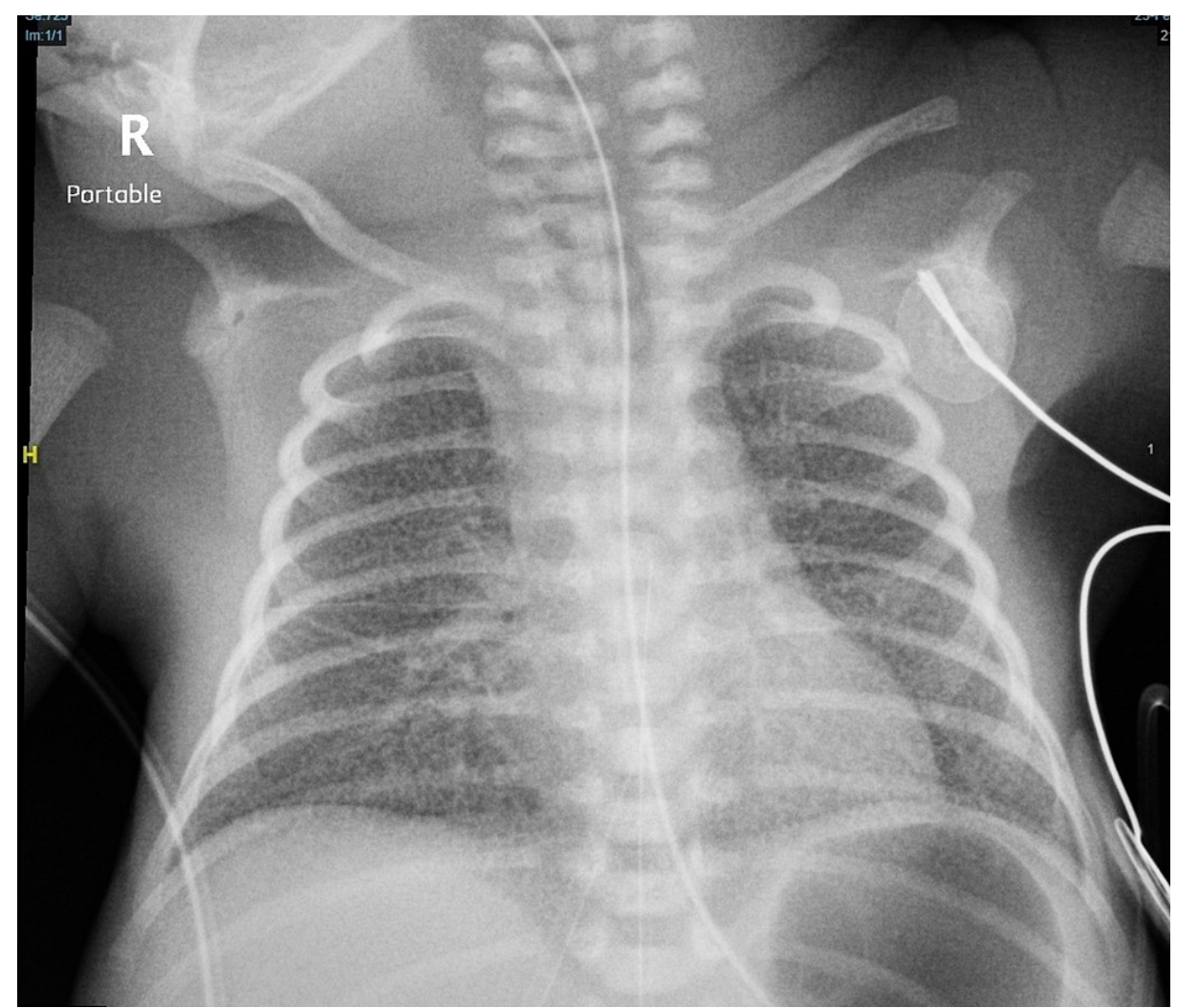

FIGURE 3: Chest radiography revealed better expansion of both lung fields compared with a previous study. However, bilateral diffuse granular infiltrate was noted.

He then developed left-sided tension pneumothorax, which required urgent intervention via chest tube insertion (Figures 4, 5). 


\section{Cureus}

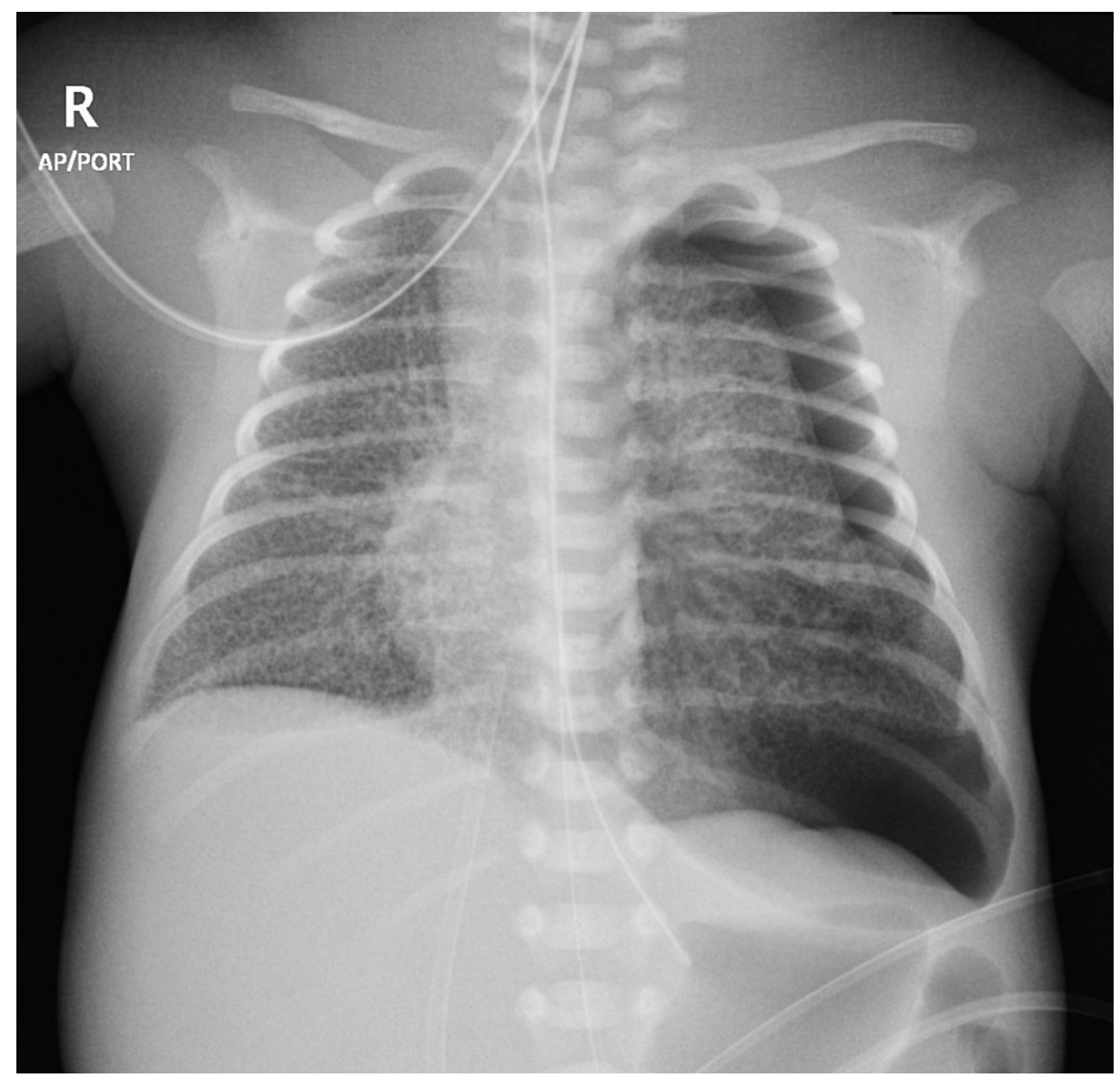

FIGURE 4: Chest radiography revealed newly developed left-sided pneumothorax. 


\section{Cureus}

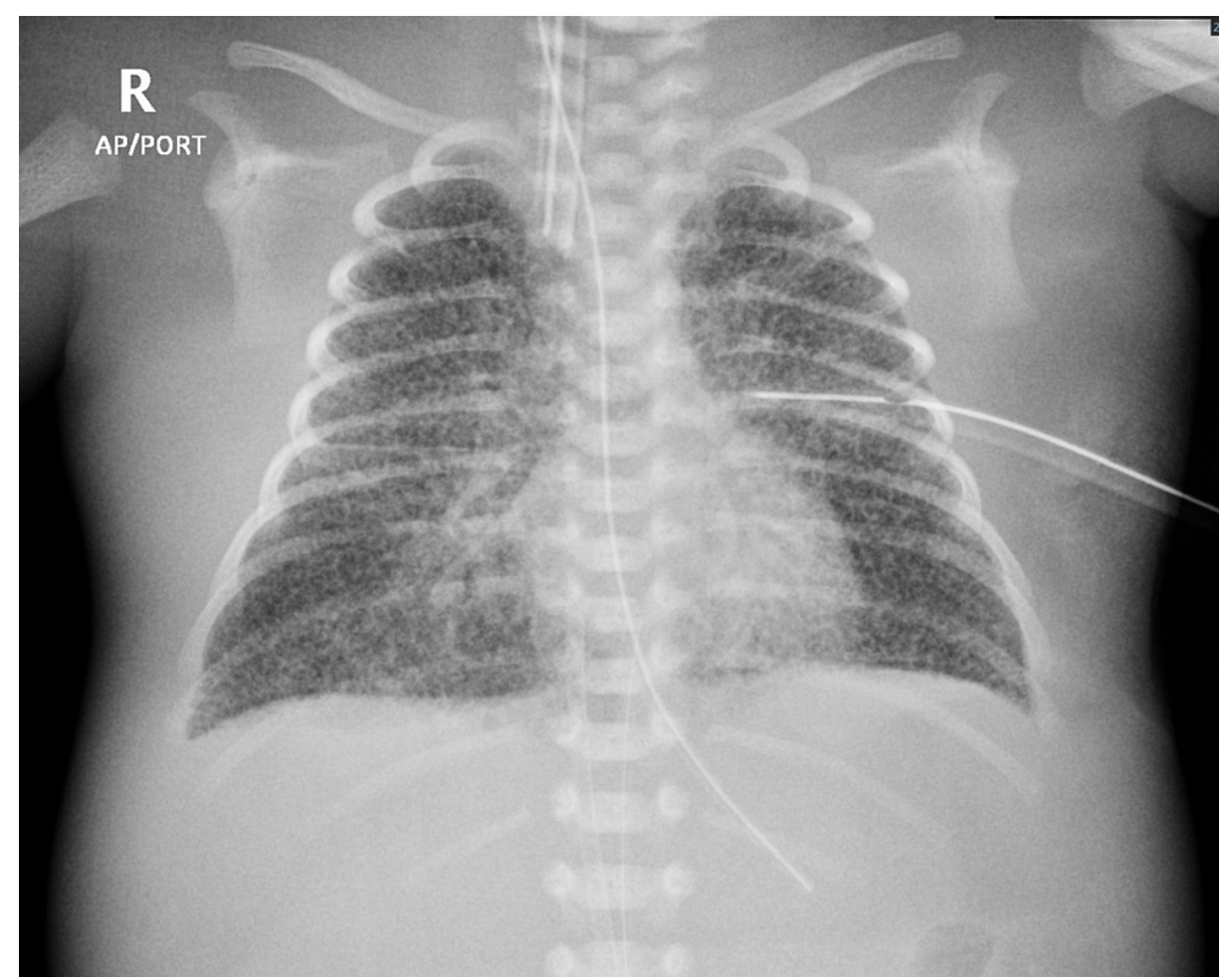

FIGURE 5: Chest radiography showed resolving pneumothorax after the insertion of left chest tube with re-expansion of the partially collapsed left lung.

The culture results remained negative. However, the C-reactive protein level slightly increased postadmission. Since the baby's condition worsened, broad-spectrum antibiotics were administered.

Based on the clinical, laboratory, and echo findings and radiological features, we sent WES, which showed the homozygous NF1 (NM_000267.3) variant (c.7127-1=/G>T P).

Despite maximum respiratory and hemodynamic support, the baby did not respond to treatment, and he died four days after birth.

\section{Discussion}

NF1 is an autosomal dominant disease with approximately $100 \%$ transmission and $50 \%$ sporadic mutations. It is characterized by a risk of developing tumors in the ectodermal and mesodermal tissues [1,6,7]. Few studies showed that patients with NF1 had a higher risk of cardiac malformations. Nevertheless, the repetition and mechanism of these manifestations are still unknown [8,9]. The condition is diagnosed based on the presence of two or more of the following conditions according to the National Institutes of Health diagnostic criteria: café au lait macules, neurofibromas, axillary/inguinal freckling, Lisch nodules, distinctive osseous lesions, glioma, and/or family history of NF [10].

PAH is an extremely rare complication of NF1. Children with fatal complications such as cerebral infarction, fatal brain tumors, and hemorrhage may die before diagnosis [9]. The association between NF1 and PAH remains unclear. NF is a cause of systemic vasculopathy. This finding increases the strength of some theories showing that pulmonary vasculopathy is the mechanism underlying this correlation $[8,11,12]$. Further, the presence of neurofibrin, which is an NF1-encoded protein that plays a role in cell growth regulation and proliferation, supports the theory of pulmonary vasculopathy [13].

NF1 can be diagnosed via imaging with ventilation-perfusion scans and a high-resolution CT scan of the chest. These methods can identify bilateral filling defects and a mosaic pattern in the lungs, representing irregular perfusion [14]. There are no clear data nor recommendations for the use of approved drugs for group $5 \mathrm{PAH}$. However, despite the risk of pulmonary venous involvement in this group, vasodilators are considered effective [15].

Thus far, there is no research confirming whether NF1 is the primary cause of PAH in the neonatal age group. However, in the current case, a CT scan of the chest and biopsy were not performed because the baby 
was not stable.

\section{Conclusions}

$\mathrm{PAH}$ is a rare fatal complication of NF1, and most cases in the literature involve adults. This case study aimed to present the possible etiology of PAH, and the results can be used as a basis for future research. Although few studies showed a higher incidence of cardiac malformation in NF1, $50 \%$ of children are born to healthy parents. However, further investigations should be performed to identify the risk of fatal complications in NF1, particularly among neonates.

\section{Additional Information}

\section{Disclosures}

Human subjects: All authors have confirmed that this study did not involve human participants or tissue. Conflicts of interest: In compliance with the ICMJE uniform disclosure form, all authors declare the following: Payment/services info: All authors have declared that no financial support was received from any organization for the submitted work. Financial relationships: All authors have declared that they have no financial relationships at present or within the previous three years with any organizations that might have an interest in the submitted work. Other relationships: All authors have declared that there are no other relationships or activities that could appear to have influenced the submitted work.

\section{References}

1. Reynolds RM, Browning GG, Nawroz I, Campbell IW: Von Recklinghausen's neurofibromatosis: neurofibromatosis type 1. Lancet. 2003, 361:1552-4. 10.1016/s0140-6736(03)13166-2

2. Nair J, Lakshminrusimha S: Update on PPHN: mechanisms and treatment . Semin Perinatol. 2014, 38:78-91. 10.1053/j.semperi.2013.11.004

3. Steinhorn RH: Neonatal pulmonary hypertension. Pediatr Crit Care Med. 2010, 11:S79-84. 10.1097/PCC.0b013e3181c76cdc

4. Zamora AC, Collard HR, Wolters PJ, Webb WR, King TE: Neurofibromatosis-associated lung disease: a case series and literature review. Eur Respir J. 2007, 29:210-4. 10.1183/09031936.06.00044006

5. Galiè N, Hoeper MM, Humbert M, et al.: Guidelines for the diagnosis and treatment of pulmonary hypertension: the task force for the diagnosis and treatment of pulmonary hypertension of the European Society of Cardiology (ESC) and the European Respiratory Society (ERS), endorsed by the International Society of Heart and Lung Transplantation (ISHLT). Eur Heart J. 2009, 30:2493-537. 10.1093/eurheartj/ehp297

6. Castle B, Baser ME, Huson SM, Cooper DN, Upadhyaya M: Evaluation of genotype-phenotype correlations in neurofibromatosis type 1. J Med Genet. 2003, 40:e109. 10.1136/jmg.40.10.e109

7. Jett K, Friedman JM: Clinical and genetic aspects of neurofibromatosis 1. Genet Med. 2010, 12:1-11. 10.1097/GIM.0b013e3181bf15e3

8. Stewart DR, Cogan JD, Kramer MR, et al.: Is pulmonary arterial hypertension in neurofibromatosis type 1 secondary to a plexogenic arteriopathy?. Chest. 2007, 132:798-808. 10.1378/chest.06-3017

9. Leppävirta J, Kallionpää RA, Uusitalo E, Vahlberg T, Pöyhönen M, Peltonen J, Peltonen S: Congenital anomalies in neurofibromatosis 1: a retrospective register-based total population study. Orphanet J Rare Dis. 2018, 13:5. 10.1186/s13023-017-0756-4

10. Gutmann DH, Aylsworth A, Carey JC, et al.: The diagnostic evaluation and multidisciplinary management of neurofibromatosis 1 and neurofibromatosis 2. JAMA. 1997, 278:51-7.

11. Gumbiene L, Petrulioniene Z, Rucinskas K, Maneikiene V, Serpytis P, Dranenkiene A, Laucevicius A: Pulmonary hypertension: a fatal complication of neurofibromatosis type 1 . Respir Care. 2011, 56:1844-8. 10.4187/respcare.01030

12. Jutant EM, Girerd B, Jaïs X, et al.: Pulmonary hypertension associated with neurofibromatosis type 1 . Eur Respir Rev. 2018, 27:180053. 10.1183/16000617.0053-2018

13. Küçük M, Öncel CR, Uçar M, Yıldırım AB: Type 1 neurofibromatosis complicated by pulmonary arterial hypertension: a case report. Turk Kardiyol Dern Ars. 2017, 45:458-61. 10.5543/tkda.2016.36897

14. Engel PJ, Baughman RP, Menon SG, Kereiakes DJ, Taylor L, Scott M: Pulmonary hypertension in neurofibromatosis. Am J Cardiol. 2007, 99:1177-8. 10.1016/j.amjcard.2006.11.072

15. Weatherald J, Savale L, Humbert M: Medical management of pulmonary hypertension with unclear and/or multifactorial mechanisms (Group 5): is there a role for pulmonary arterial hypertension medications?. Curr Hypertens Rep. 2017, 19:86. 10.1007/s11906-017-0783-5 